\title{
Energy Absorption by the Membrane Rafts in the Modulated Electro-Hyperthermia (mEHT)
}

\author{
Edina Papp¹, Tamás Vancsik², Eva Kiss², Oliver Szasz ${ }^{3}$ \\ ${ }^{1}$ Faculty of Information Technology and Bionics, Pazmany P. Catholic University, Budapest, Hungary \\ ${ }^{2} 1$ st Department of Pathology and Experimental Cancer Research, Semmelweis University, Budapest, Hungary \\ ${ }^{3}$ Department of Biotechnics, St. Istvan University, Godollo, Hungary \\ Email: biotech@gek.szie.hu
}

How to cite this paper: Papp, E., Vancsik, T., Kiss, E. and Szasz, O. (2017) Energy Absorption by the Membrane Rafts in the Modulated Electro-Hyperthermia (mEHT). Open Journal of Biophysics, 7, 216-229. https://doi.org/10.4236/ojbiphy.2017.74016

Received: September 27, 2017

Accepted: October 27, 2017

Published: October 30, 2017

Copyright (c) 2017 by authors and Scientific Research Publishing Inc. This work is licensed under the Creative Commons Attribution International License (CC BY 4.0).

http://creativecommons.org/licenses/by/4.0/

\section{(c) (i) Open Access}

\begin{abstract}
Aim: Heating by nanoparticles, which are located in the tissue to be treated, is a well-recognized method in hyperthermic oncology. Our objective is to investigate selective, nanoscopic heating without concentrating extra artificial nanoparticles. We have in silico calculation to study the heating of the transmembrane protein clusters (rafts) on cell-membrane. The transmembrane protein domains have significantly higher dielectric constant than their lipid neighborhood in the membrane. This difference causes a local gradient in the Specific Absorption Rate (SAR), which could be a factor of heating of the membranes locally, as well as exciting the receptors for various signal transduction in the cells. We suppose that this process determines the observed cellular effects of modulated electro-hyperthermia (mEHT, trade-name: oncothermia). Materials and Methods: In silico models with highly specialized software (Computer Simulation Technology (CST), Darmstadt, Germany) were performed visualizing the selectivity for the membrane domains. Local raft models were created to simulate the electromagnetic (EM) effect of a 13.56 $\mathrm{MHz}$ excitation between two perfect electrical conductor plates, simulating the equipotential conditions of the sides of the membrane in the vicinity of the raft. The simulations were performed with near-field (EQS) solver of CST. The electric field, current density, and electric loss density were monitored by the simulations. The applied material properties and parameters refer to the recent literature. Results: In silico models show ten times higher energy-absorption of the transmembrane domains than that of its lipid-membrane surrounding, and intra- and extracellular neighborhood. Depending on the size, orientation, and location of the membrane rafts, the value of SAR varies, but we use only two simplified models to see the absorption properties. Taking into account the characteristics of the EM field effects we showed that the selective energy-absorption increased further by the cell-cell interactions. The
\end{abstract}


model-calculation could confirm the opportunity of the local membrane heating. Conclusion: Our results indicate the heating in nanoscopic range with energy-absorption by the transmembrane proteins. The heated protein-clusters (membrane rafts) are used the same way as the artificial nanoparticles, while these absorbers are natural parts of the biological system.

\section{Keywords}

Modulated Electro-Hyperthermia (mEHT), Nanoheating, Membrane Raft, Selection

\section{Introduction}

One of the main objectives of modulated electro-hyperthermia (mEHT) [1] is its selective heating [2], which is supposed to be by energy-absorption of the transmembrane protein clusters (rafts) [3]. However, the measurement of the effect in nano range is highly complicated. The development of information technology allows simulating the radio-frequency (RF) induced electromagnetic (EM) field and its absorbed energy in model structures.

The main components of the cell membrane are sphingolipid, cholesterol, steroid, carbohydrate and transmembrane proteins. The rafts are structured parts of the membrane, a cluster of transmembrane proteins, and contain high proportion of saturated lipids and cholesterols as well [4]. The cholesterol and protein content increase the stability of the membrane. Furthermore, proteins are responsible for the structure and signal transduction, functioning like receptors on the surface of the membrane. The rafts are just the $2 \%$ of the membrane components but give the $50 \%$ of the membrane mass due to their size, [5]. The main part of the proteins is clustered in raft domains. They form the $25 \%-60 \%$ of the raft depending on the location of dynamic proteins, [6]. These ordered domains have high lateral mobility in the membrane [7], which allows their easy shifting by the applied electric field, situating in the most optimal absorption position.

The size of the membrane rafts depends on the ratio of protein and lipid content, which differs in their location and could change by time. The geometry of the planar rafts in the recent literature is $25-700 \mathrm{~nm}, 100-200 \mathrm{~nm}$ and $10-100$ $\mathrm{nm}$ average diameter, [8] [9] [10]. Of course, the thickness of these domains is higher (due to the high protein content) than the non-structured part of the membrane which is only about $5 \mathrm{~nm}$ [11]. Furthermore, the cholesterol which wedged in the proteins widens perpendicular the transmembrane region of the domain.

The dielectric constant and the conductivity determine the electric properties of the membrane and the rafts. The raft and its micro-environment have a considerable diversity, which complicates its average characterization. The dielectric constant (relative permittivity, $\varepsilon_{r}$ ) of the intra- and extracellular space is approx. 
$\mathcal{\varepsilon}_{r} \approx 73$ [5], showing large displacement field: $\mathrm{D} \approx \mathcal{\varepsilon}_{r} \cdot E$. The membrane layer has a low dielectric constant, $\left(\varepsilon_{r} \approx 2\right)$. However, the membranes are heterogenous. The layers of phospholipid heads and tails have different dielectric constants in the shell model, [12] [13] [14] [15] [16].

The raft domain contains a high portion of protein; therefore, this region has undoubtedly higher permittivity than its membrane neighborhood. The average dielectric constant of the raft domain takes into consideration the proteins in the cluster. The protein permittivity has multiple variants in the literature. There is measurement showing an extreme high $\varepsilon_{\text {protein }} \approx 6300$ value in the integral protein next to the low $\varepsilon_{\text {lipid }} \approx 2$ value in the lipid region, and the transmembrane region of the protein also has low permittivity because the ability of polarization is blocked in this area [17]. In other membrane measurement $\varepsilon_{m}=12.5$ (with 1.6 standard deviations) [18]. This high value is probably a local peak in the measured average dielectric value of protein including membrane.

The transmembrane protein clusters have even more heterogeneity and complex interactions, and so their simulation and measurements are more complicated. The hydrophobic region of the proteins shows low dielectric constant $2<$ $\varepsilon_{\text {protein }}<5$; however, the outer regions with bounded water increase up to more than $\varepsilon_{\text {protein }}>100$ in some regions, and proves the extreme values in some cases [17]. The water bound to the protein further increases the average dielectric constant, like it is shown by the Kirkwood-Fröhlich approximation in 21 types of proteins in water solution, [19]. Simulations [20] show that the protein dielectric constant was $\varepsilon_{\text {protein }} \cong 6-7$ in the inner protein region and $\varepsilon_{\text {protein }} \cong 20-30$ on its wet surface. Generally, although the cholesterol and lipid contents of the raft domain cause decreasing in the relative permittivity of the inner raft area (2 $<\mathcal{E}_{\text {raft }}<5$ ), but the high density of protein chain ends lead to an outstanding raft region with high relative permittivity $\left(40<\varepsilon_{\text {raft protein }}<80\right)$, [21]. We assume the dielectric constant of the complex membrane rafts as $\varepsilon_{\text {raft }} \approx 40$.

The electric conductivity also shows the difference between the raft and non-raft part of the membrane. The average conductivity of the cell membrane is $3 \times 10^{-7} \mathrm{~S} / \mathrm{m}$, [5]. In the membrane having high proportions of transmembrane proteins nearly ten times higher conductivity was measured, [22]. Models of the added protein domains with different concentration into the lipid layer showed between one and three orders of magnitude higher conductivity in the presence of protein fractions than the lipid membrane alone [23]. We conclude that the high protein portion of raft domain causes at least ten times higher electric conductivity, which well identifies the rafts by the forced RF-current. In the case of multilayer model, the conductivity of the outer part of rafts is estimated nearly $3 \times 10^{-3} \mathrm{~S} / \mathrm{m},[24]$.

The absorbed energy heats the mass of the raft. The mass determines their developed temperature. The membrane mass is made up of $52 \%$ protein, $40 \% \mathrm{li}$ pid, and $8 \%$ carbohydrate, [25]. The main part of membrane proteins is located in membrane rafts. The mass density of the non-raft membrane region is examined in several projects, [26] [27] [28]. The mass density of the inner parts of 
the protein chains is lower than their surfaces, but of the mass density of the outer part of the complex raft is higher than the value of the electrolyte. The average mass density of electrolyte is $1000 \mathrm{~kg} / \mathrm{m}^{3}$, while of the lipid is approx. 900 $\mathrm{kg} / \mathrm{m}^{3}$, [28] [29] [30]. The presence of sphingomyelins and cholesterols (which are typical in the raft) increases of the membrane mass density, which is enhanced further by the presence of transmembrane proteins, [31] [32] [33] [34]. Taking these facts into consideration the mass density of membrane rafts is estimated pretty high, up to $1150 \mathrm{~kg} / \mathrm{m}^{3}$.

Our objective is to calculate the specific energy distribution in the above described well heterogeneous membrane structures, with particular emphasis of the energy-absorption of their rafts. The summary of the values of parameters, which are used in this article to examine the electric loss distribution in the membrane raft domains is presented in Table 1.

\section{Material and Methods}

The CST EM Studio from Computer Simulation Technology software (Darmstadt, Germany) [35] was used to simulate the electromagnetic (EM) field effect on the 3D cellular models. The calculation is based on the Finite Integration Technique (FIT) [36] which enables to solve the Maxwell equations under certain conditions applying a mesh for numerical calculation. Considering the created structure and material properties of the model and the defined excitation conditions the software calculates the direction and the magnitude of EM field vectors for each mesh unit. Due to the extremely high mesh number, the simulation resolution does not allow precise solution; therefore, in our cellular models, a homogenous membrane layer was generated.

Table 1. Material properties which used the simple and complex raft simulations (based on the literature values).

\begin{tabular}{|c|c|c|c|c|}
\hline Material & $\begin{array}{l}\text { Dielectric } \\
\text { constant }\end{array}$ & $\begin{array}{l}\text { Conductivity } \\
(\mathrm{S} / \mathrm{m})\end{array}$ & $\begin{array}{l}\text { Mass density } \\
\left(\mathrm{kg} / \mathrm{m}^{3}\right)\end{array}$ & $\begin{array}{l}\text { Underlying } \\
\text { References }\end{array}$ \\
\hline Extracellular space & 72.5 & 1.2 & 1000 & \multirow{3}{*}{$\begin{array}{l}\text { Kotnik et al., } 2000 \text { [5] } \\
\text { Campello et al., } 2014 \text { [31] }\end{array}$} \\
\hline Intracellular space & 72.5 & 0.3 & 1000 & \\
\hline Membrane & 2 & $3 \times 10^{-7}$ & 900 & \\
\hline \multirow[b]{2}{*}{ Raft } & \multicolumn{3}{|c|}{ Simple Model } & \\
\hline & 40 & $3 \times 10^{-6}$ & 1150 & $\begin{array}{c}\text { Pitera et al., } 2001 \text { [19] } \\
\text { Banerjee et al., } 1981 \text { [24] } \\
\text { Heikelä et al., } 2006 \text { [34] } \\
\text { Waxham et al., } 2007 \text { [35] }\end{array}$ \\
\hline \multicolumn{5}{|c|}{ Complex model } \\
\hline Raft-inner & 4 & $3 \times 10^{-6}$ & 1150 & $\begin{array}{l}\text { Guest et al., } 2011 \text { [20] } \\
\text { Li et al., } 2013 \text { [21] } \\
\text { Starke et al., } 2006 \text { [23] } \\
\text { Banerjee et al., } 1981 \text { [24] }\end{array}$ \\
\hline Raft-outer & 40 & $3 \times 10^{-3}$ & 1050 & $\begin{array}{l}\text { Heikelä et al., } 2006 \text { [34] } \\
\text { Waxham et al., } 2007 \text { [35] }\end{array}$ \\
\hline
\end{tabular}


Our primary attention focused on the local electric field distribution in the membrane raft and its environment. The first model represents a homogenous raft domain embedded in the membrane layer (see Figure 1). The flat membrane was stretched between two parallel circular plates in the middle. The diameter of the electrodes was $3 \mu \mathrm{m}$, the thickness was $50 \mathrm{~nm}$, and the material was Perfect Electrical Conductor (PEC), modelized the equipotential conditions at the two sides of the membrane. The distance between the plates was defined to $2 \mu \mathrm{m}$ plus $5 \mathrm{~nm}$ (which was the thickness of the electrolytes together and the membrane). The raft domain was placed in the middle of the membrane with the same thickness. The diameter of the raft was $1 \mu \mathrm{m}$. The material parameters of the model correspond to Table 1.

The second local model was a complex three-layer raft with the similar conditions as in the homogeneous except with the changed thickness and some material parameters: the inner raft was increased to $6 \mathrm{~nm}$ and the outer raft area was represented with two $2 \mu \mathrm{m}$ thick layers, (see Table 1 ).

The simulating frequency in both cases was $13.56 \mathrm{MHz}$. The maximum wavelength in the model was much higher than the measuring volume, therefore, the low-frequency solver was used. Open boundary conditions were defined with adaptive tetrahedral mesh division. The model was divided into approximately three million tetrahedrons. For excitation $100 \mathrm{mV}$ effective voltage difference was defined between the two electrode plates, simulating the membrane potential by creating approx. $1.1 \times 10^{7} \mathrm{~V} / \mathrm{m}$ electric field in the membrane.

\section{Results}

The electric field, current density, electric energy and electric loss density at 13.56 $\mathrm{MHz}$ were calculated in our present simulations. Figure 2 and Figure 3 show the calculated field distributions in the simple and the complex cases, respectively. The E-field at the raft boundary is significantly higher than in the

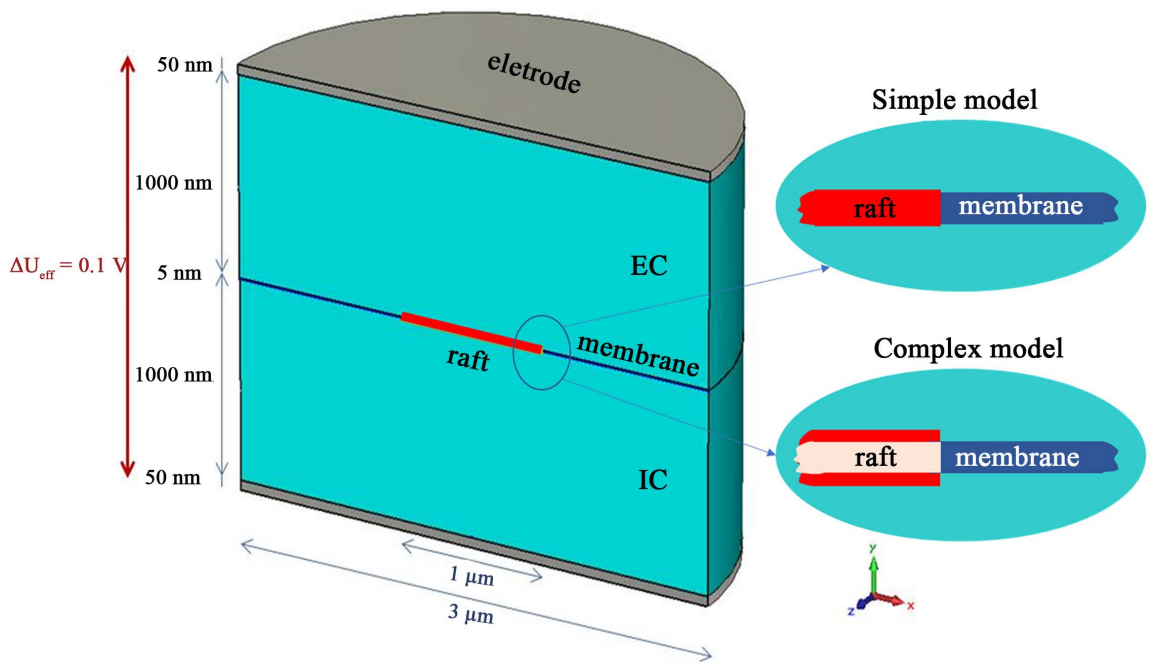

Figure 1. Local membrane raft models. The connected parts of the simple and complex models are in the inserts. 


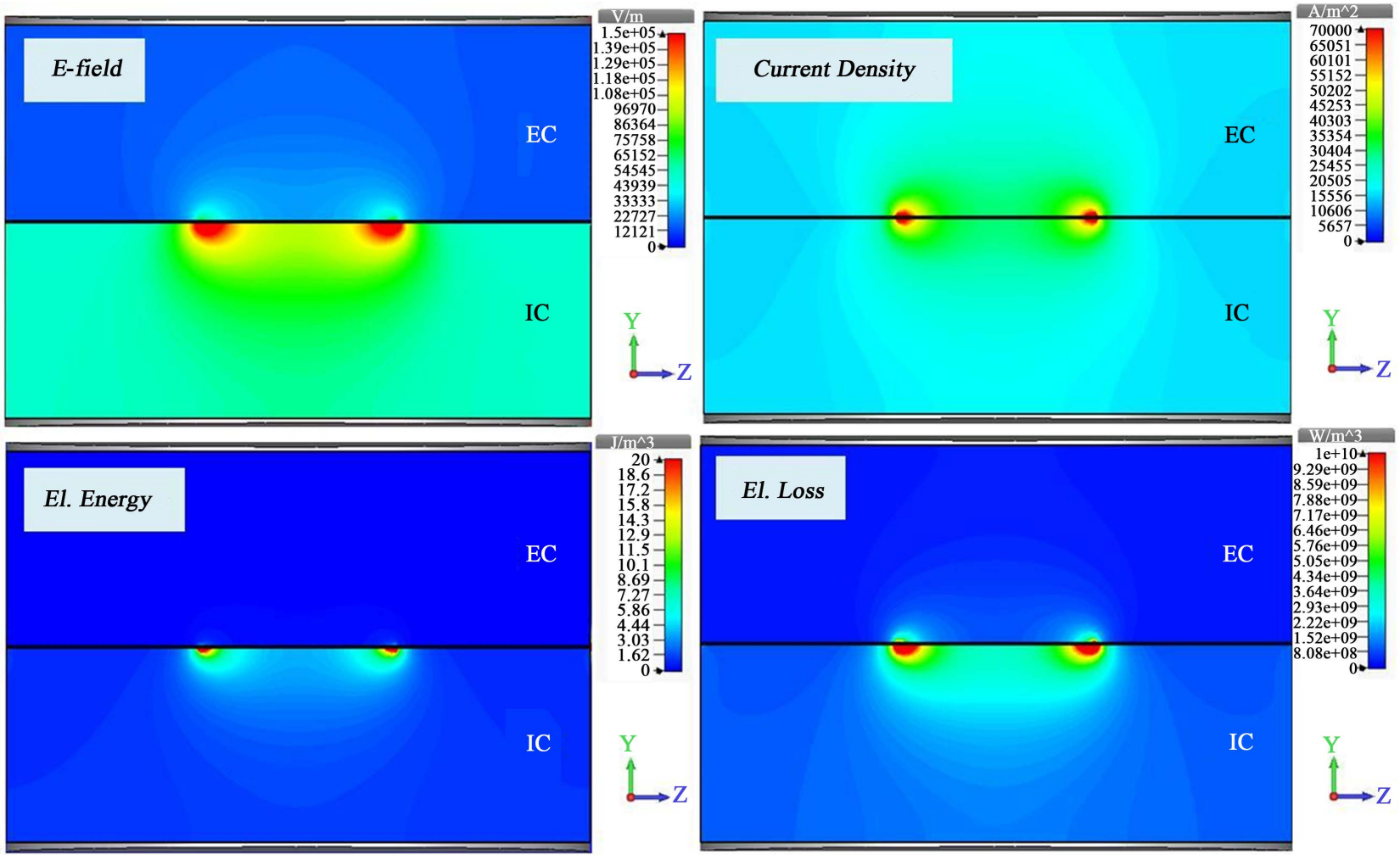

Figure 2. 2D simulation results of electric field, current density, electric energy and electric loss density at $13.56 \mathrm{MHz}$ in the case of simple model. The cutting plane was at the symmetry axis $x=0$. (EC: Extracellular space, IC: Intracellular space).

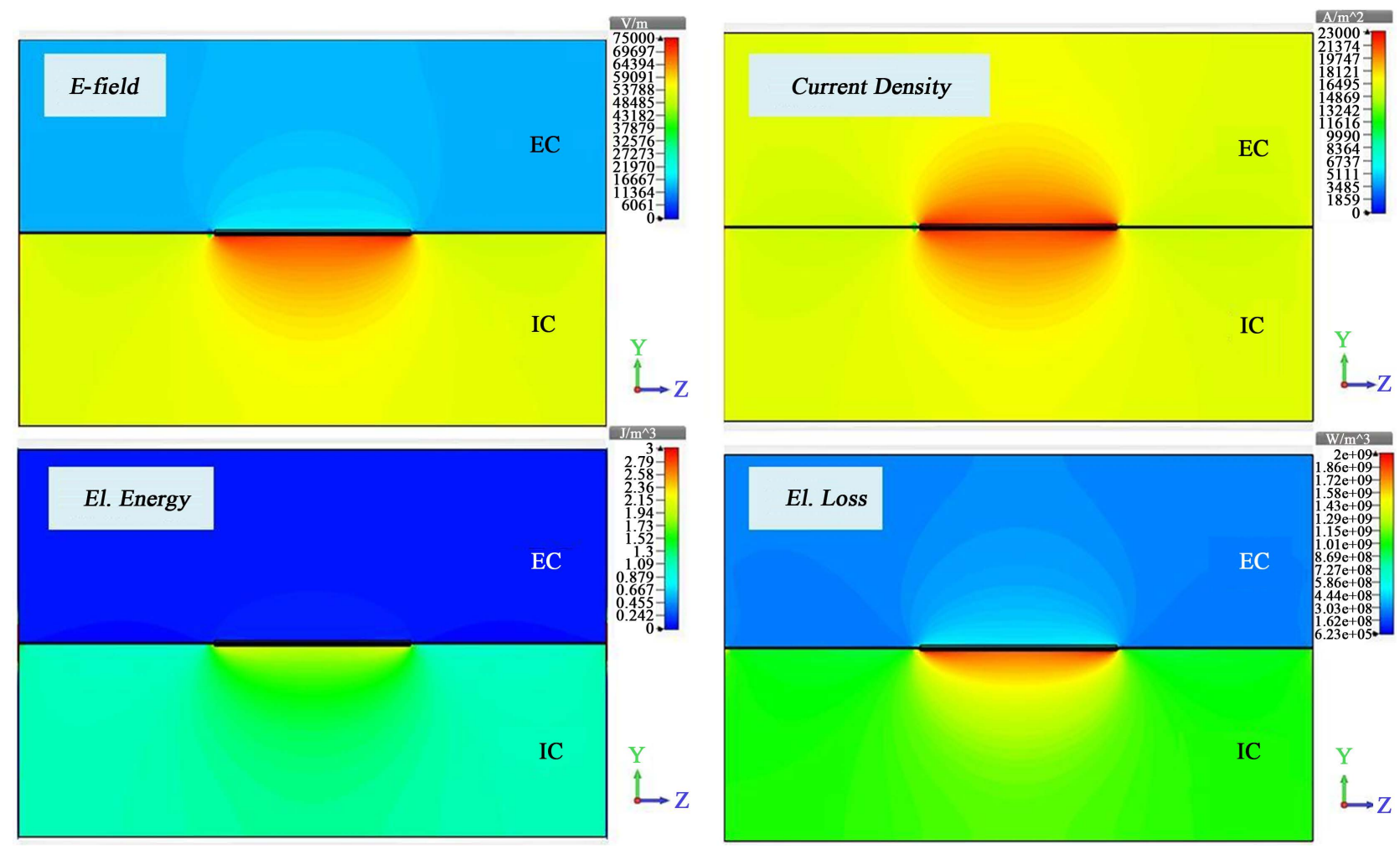

Figure 3. 2D simulation results of electric field, current density, electric energy and electric loss density at $13.56 \mathrm{MHz}$ in the case of a complex model. The cutting plane was at the symmetry axis $x=0$. (EC: Extracellular space, IC: Intracellular space). 
electrolyte. Furthermore, we can see a discrepancy between the extracellular (EC) and intracellular (IC) values also due to the conductivity differences. In the simple raft model, local peaks appear at the border of the raft and membrane. In the complex model, these peaks are significantly weaker. The whole raft environment has almost the same high E-field. We observed it in all calculated field distributions. The current density shows significantly higher value at the raft.

The supplied energy can be divided into two parts. One is the stored energy, and the other is the loss, which transforms into heat. Therefore, the loss distribution gives essential information to estimate the early heat distribution. Each result shows that the high differences in the material properties give a massive peak in the investigated domain (see Figure 4). The absorption is much higher in the rafts than in the non-raft part of the cell membrane.

The Specific Absorption Rate (SAR) is the quotient of electric loss (Pd) and mass (m), which is evidently calculated from the electric loss density (see Figure 5). The connection between the SAR and the temperature change when the conduction heat transfer is negligible:

$$
\Delta T=\frac{Q}{c_{p} m}=\frac{P_{d} * \Delta t}{c_{p} m}=\frac{S A R * \Delta t}{c_{p}}
$$

where $c_{p}$ is the specific heat in isobar conditions, $Q$ is the heat-energy and $\Delta t$ is the time of observation. Consequently, the partial derivative of temperature is well approximated by the SAR. The calculated temperature change is remarkable at the raft domain. The time interval $(\Delta t)$ was chosen to 0.01 second. Figure 6 shows the temperature gradient of the simple and complex raft model. The heated mass of the complex model is definitely less than in the simple one so that less energy may heat it for us to a higher temperature.

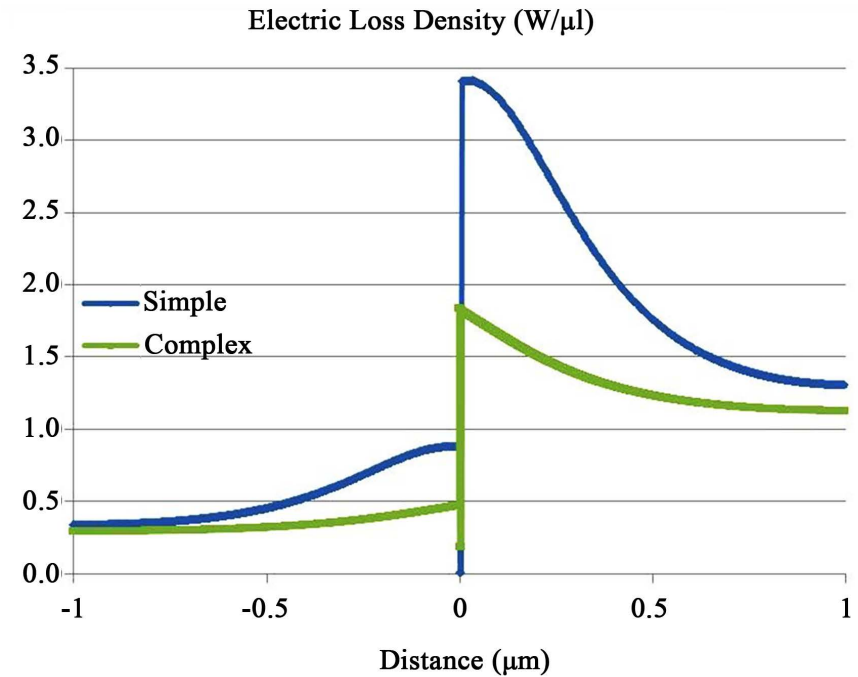

(a)

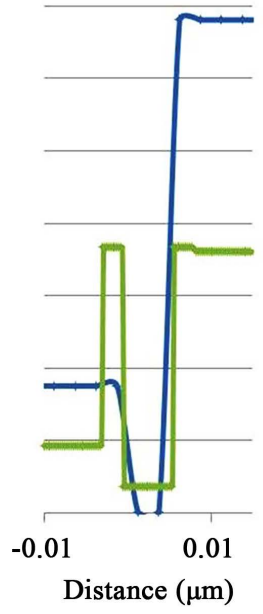

(b)

Figure 4. Electric Loss Density in the simple and complex model at the vertical symmetry axis. The negative distance is the loss in the extracellular space; the positive one is the loss of the intracellular space. The jump at zero is the loss in the raft (a). The absorption of the raft is magnified (b). 
$\operatorname{SAR}(\mathrm{W} / \mu \mathrm{g})$

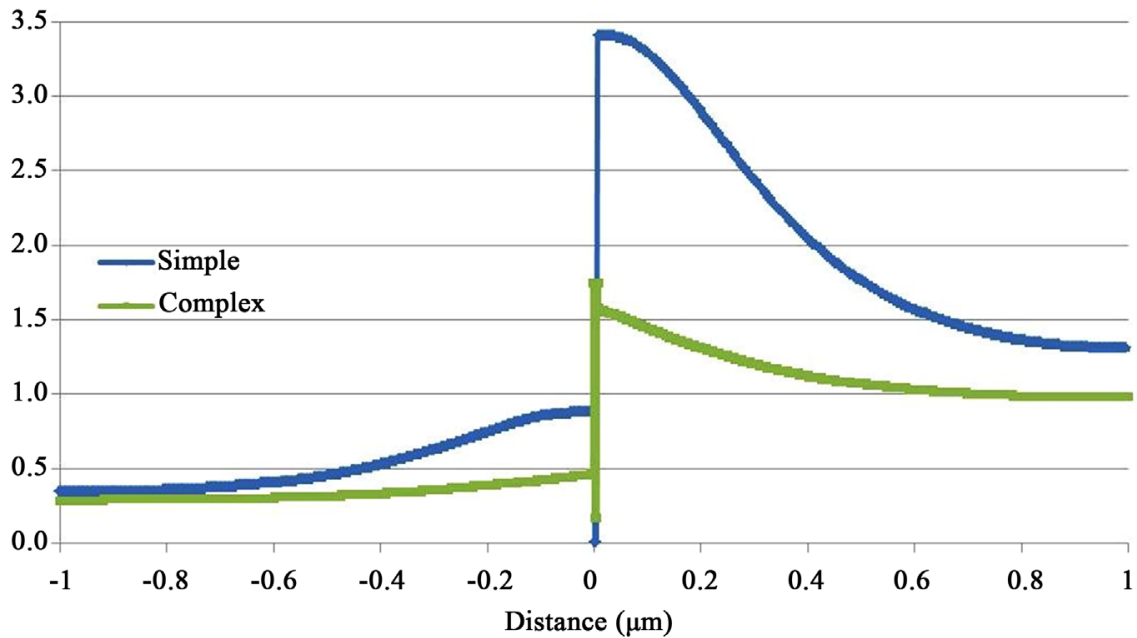

Figure 5. Specific Absorption Rate (SAR) in the simple and complex model at the vertical symmetry axis. The negative distance is the loss in the extracellular space; the positive one is the loss of the intracellular space. The jump at zero is the loss in the raft.

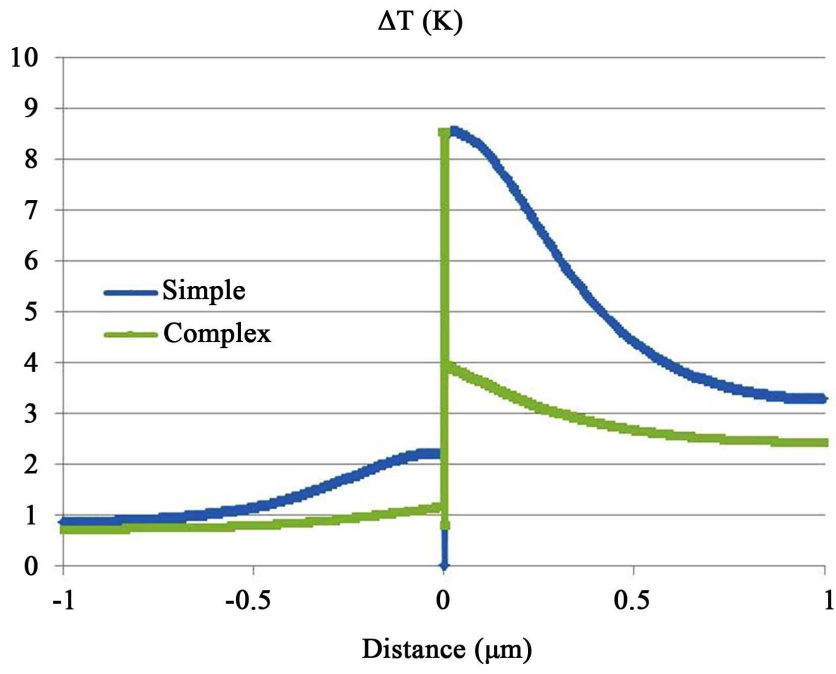

(a)

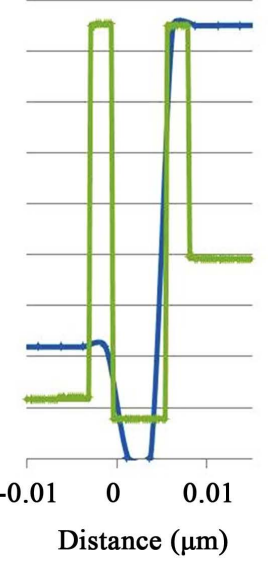

(b)

Figure 6. Temperature change $(\Delta \mathrm{T})$ in the simple and complex model at the vertical symmetry axis. The negative distance is the loss in the extracellular space; the positive one is the loss of the intracellular space. The jump at zero is the temperature change in the raft (a). The temperature of the raft is magnified (b).

\section{Discussion}

The theoretical model-calculation of mEHT induced nanoheating effect by EM field simulations shows a high selectivity of the energy-absorption. The simulation does not consider some further complexity of the rafts like the average permittivity depends on the type of amino acids as well [21]. Based on the 91 examined proteins the average dielectric constant is in the interval $11.0<\varepsilon_{\text {protein }}<$ 25.6. The highest values of $\varepsilon_{\text {protein }}$ are found for lysine, arginine, glutamine, and aspartate. The detected dielectric constant considerably depends on the method 
and the configuration of the actual measurement, mainly on the water-content of the protein. The permittivity of the protein is more than two times higher at low $\mathrm{pH}$ than at high $\mathrm{pH}$, and the surrounding electrolyte, as well as the temperature, also influence remarkably the observed values, [19], [37]. By this way, the low-pH values of cancerous tumors are increasing the permittivity of the rafts, which helps their selection by the electric field. Consequently, the selection values of our present simulation can be even more robust so that we may consider this calculation as the lower limit of the selectivity.

The local heating occurs on the membrane raft domains, which is the functional part of the membrane. The comparison of the simple and complex membrane raft models shows that the environmental loss in the near vicinity of the raft is less in the complex model than at the homogeneous one. However, the value of the loss in the inner part has the opposite change. The gradient between the layers causes this effect. Calculations show that at least one order of magnitude extra energy absorption can be observed in the rafts in both cases, which proves the selectivity of the membrane raft. The magnitude of the derived SAR value at the membrane raft corresponds well to the literature results of magnetic nanoparticles, [38].

The complex raft model represents a more localized temperature gradient, (Figure 6). Furthermore, the temperature in the outer part of the raft is nearly the same as in the local neighborhood of the homogeneous raft model at the given $\Delta t$. Therefore, we can accept approx. $8.5^{\circ} \mathrm{C}$ temperature change in the protein tail-end region in the raft as a local heating of the micro-domain. The electric field and the increased temperature has a strong synergy [39].

The simulation results of cellular models correspond with the theoretical considerations [3], and the experimental results, which is measured by DIL die of the membrane and its fluorescence is calibrated on temperature. The measured membrane temperature was in average $6^{\circ} \mathrm{C}$ higher in the selective heating than in the water-bath on the same temperature measured in vitro by HT29 human hepatocellular carcinoma cell-line [40]. The crucial detailed investigation was performed on U937 human lymphoma cell-line, where the nano selection effect was used and showed its thermal, Arrhenius-plot too, [41]. Using the advantages of the present selection mechanisms a new kind of hyperthermia was developed: the modulated electro-hyperthermia (mEHT), in which the nano range effect on the rafts plays a crucial role, [42] [43].

The selectively heated rafts excite numerous signal transduction pathways [44], and produce extrinsic apoptosis signals [45]. In the case of well-applied excitations, these create a spatiotemporal production of particular molecules (damage-associated molecular pattern, DAMP), and its consequence could be immunogenic cell-death (ICD), [46].

The high energy absorption at membrane raft appears in cellular level also. Furthermore, the results of a seven-cell model, where the cell-cell micro-contacts are raft domains, present high local electric loss peaks at the connection areas, especially in the vertical cell contacts (Figure 7). 


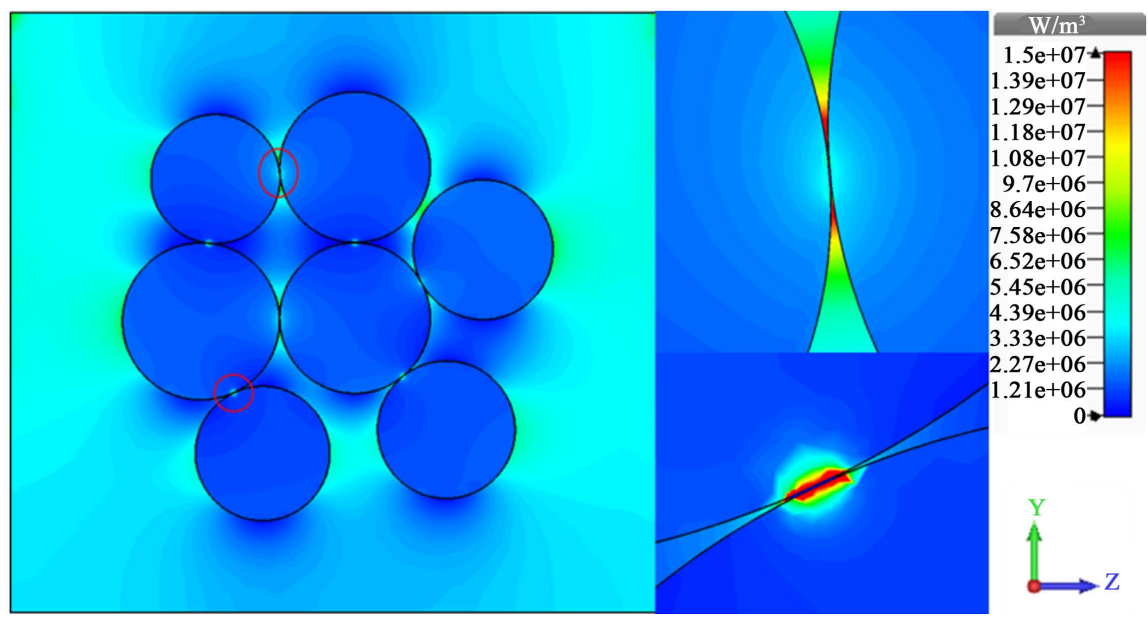

Electric loss

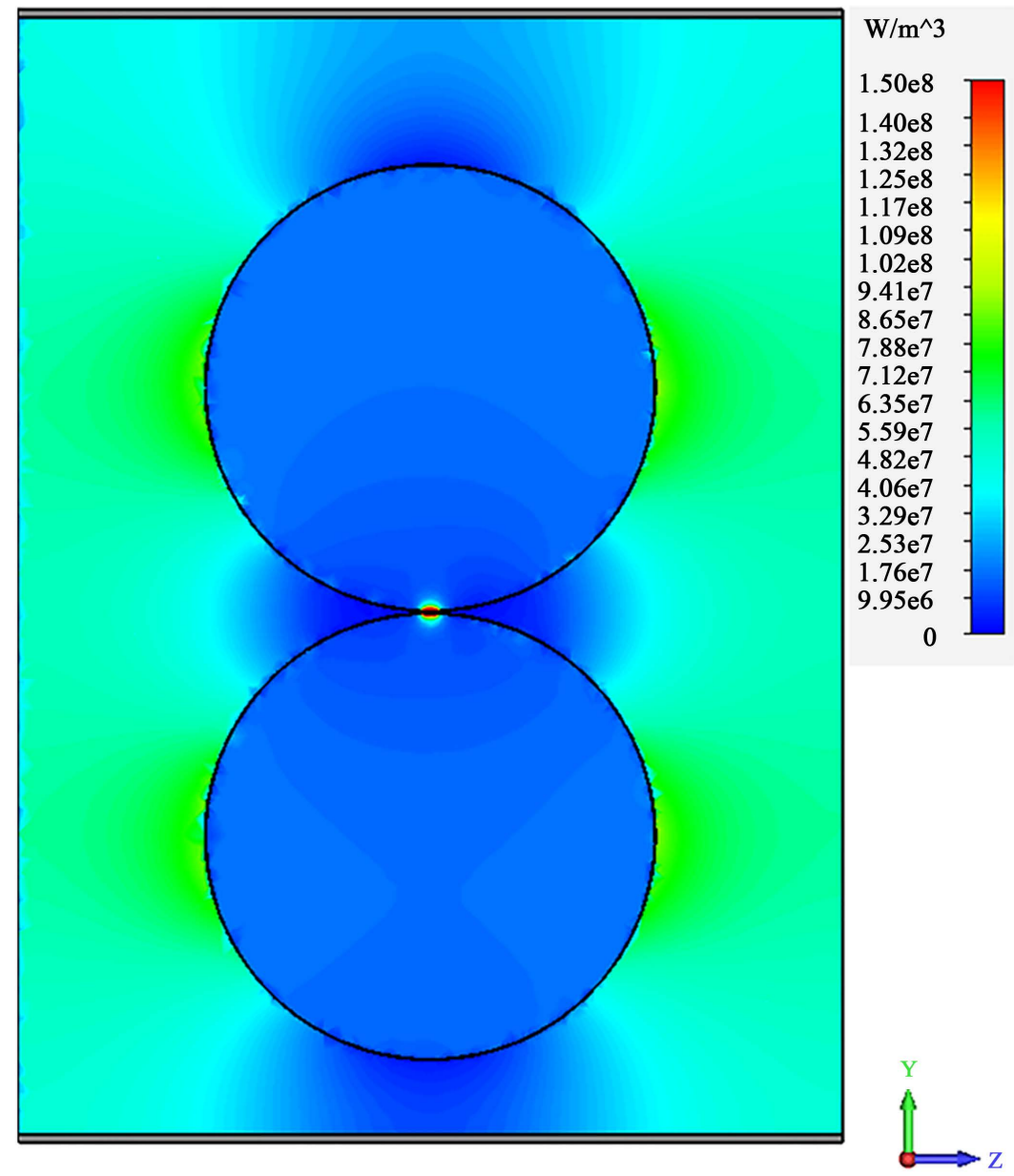

Figure 7. Extra energy-loss happen by touching microdomains at the neighboring cells.

The selection makes the high-preciosity of the energy targeting possible [47], accompanied with high efficacy as well [48]. This special energy-targeting could be one of the factors of the apoptosis induction, as well as the production of the DAMP and ICD, as a basis of tumor-vaccination [49]. 


\section{Conclusion}

These confirm that mEHT can cause specific energy-absorption in the membrane rafts, which carry many signal-receptors and are involved in multiple functional signal pathways.

\section{Acknowledgements}

This research was supported by the Hungarian Competitiveness and Excellence Programme grant (NVKP_16-1-2016-0042).

\section{References}

[1] Szasz, A. (2013) Challenges and Solutions in Oncological Hyperthermia. Thermal Medicine, 29, 1-23. https://doi.org/10.3191/thermalmed.29.1

[2] Szasz, O., Szasz, M.A., Minnaar, C. and Szasz, A. (2017) Heating Preciosity-Trends in Modern Oncological Hyperthermia. Open Journal of Biophysics, 7, 116-144. https://doi.org/10.4236/ojbiphy.2017.73010

[3] Vincze, G., Szigeti, G., Andocs, G. and Szasz, A. (2015) Nanoheating without Artificial Nanoparticles. Biology and Medicine, 7, 249.

http://www.omicsonline.com/open-access/nanoheating-without-artificial-nanoparti cles-0974-8369-1000249.php?aid=61783

[4] Thomas, S., Preda-Pais, A., Casares, S. and Brumeanu, T.D. (2004) Analysis of Lipid Rafts in T Cells. Molecular Immunology, 41, 399-409.

https://doi.org/10.1016/j.molimm.2004.03.022

[5] Kotnik, T. (2000) Theoretical Evaluation of the Distributed Power Dissipation in Biological Cells Exposed to Electric Fields. Bioelectromagnetics, 21, 385-394. https://doi.org/10.1002/1521-186X(200007)21:5<385::AID-BEM7>3.0.CO;2-F

[6] Nicolau, D.V., Burrage, K., Parton, R.G. and Hancock, J.F. (2006) Identifying Optimal Lipid Raft Characteristics Required to Promote Nanoscale Protein-Protein Interactions on the Plasma Membrane. Journal of Molecular Cell Biology, 26, 313 323. https://doi.org/10.1128/MCB.26.1.313-323.2006

[7] Nicolson, G.L. (2014) The Fluid-Mosaic Model of Membrane Structure: Still Relevant to Understanding the Structure, Function and Dynamics of Biological Membranes after More than 40 Years. Biochimica et Biophysica Acta, 1838, 1451-1466. https://doi.org/10.1016/j.bbamem.2013.10.019

[8] Dharia, S. (2011) Spatially and Temporally Resolving Radio-Frequency Changes in Effective Cell Membrane Capacitance. University of Utah, Salt Lake City.

[9] Pike, L.J. (2003) Lipid Rafts: Bringing Order to Chaos. The Journal of Lipid Research, 44, 655-667. https://doi.org/10.1194/jlr.R200021-JLR200

[10] Gramse, G., Dols-Perez, A., Edwards, M.A., Fumagalli, L. and Gomila, G. (2013) Nanoscale Measurement of the Dielectric Constant of Supported Lipid Bilayers in Aqueous Solutions with Electrostatic Force Microscopy. Journal of Biophysics, 104, 1257-1262. https://doi.org/10.1016/j.bpj.2013.02.011

[11] Andersen, O.S., Koeppe, I.I. and Roger, E. (2007) Bilayer Thickness and Membrane Protein Function: An Energetic Perspective. Annual Review of Biophysics and Biomolecular Structure, 36, 107-130.

https://doi.org/10.1146/annurev.biophys.36.040306.132643

[12] Stern, H.A. and Feller, S.E. (2003) Calculation of the Dielectric Permittivity Profile for a Nonuniform System: Application to a Lipid Bilayer Simulation. The Journal of 
Chemical Physics, 118, 3401. https://doi.org/10.1063/1.1537244

[13] Nymeyer, H. and Zhou, H.-X. (2008) A Method to Determine Dielectric Constants in Nonhomogeneous Systems: Application to Biological Membranes. Biophysical Journal, 94, 1185-1193. https://doi.org/10.1529/biophysj.107.117770

[14] Tanizaki, S. and Feig, M. (2005) A Generalized Born Formalism for Heterogeneous Dielectric Environments: Application to the Implicit Modeling of Biological Membranes. The Journal of Chemical Physics, 122, 1-13. https://doi.org/10.1063/1.1865992

[15] Raudino, A. and Mauzerall, D. (1986) Dielectric Properties of the Polar Head Group Region of Zwitterionic Lipid Bilayers. Biophysical Journal, 50, 441-449.

[16] Kirkpatrick, D.S., McGinness, J.E., Moorhead, W.D., Corry, P.M. and Proctor, P.H. (1978) High-Frequency Dielectric Spectroscopy of Concentrated Membrane Suspensions. Biophysical Journal, 24, 243-245.

[17] Smith, C. (1986) High Sensitivity Biosensors and Weak Environmental Stimuli. Proc Colloq Bioelectron. Biosensors. UCNW, Bangor, 17-19 April 1985.

[18] Pitera, J.W., Falta, M. and Gunsteren, W.F. (2001) Dielectric Properties of Proteins from Simulation: The Effects of Solvent, Ligands, $\mathrm{pH}$, and Temperature. Biophysical Journal, 80, 2546-2555.

[19] Guest, W.C., Cashman, N.R. and Plotkin, S.S. (2011) A Theory for the Anisotropic and Inhomogeneous Dielectric Properties of Proteins. Physical Chemistry Chemical Physics, 13, 6286-6295. https://doi.org/10.1039/c0cp02061c

[20] Li, L., Li, C., Zhang, Z. and Alexov, E. (2013) On the Dielectric "Constant" of Proteins: Smooth Dielectric Function for Macromolecular Modeling and Its Implementation in DelPhi. Journal of Chemical Theory and Computation, 9, 2126-2136. https://doi.org/10.1021/ct400065j

[21] Starke-Peterkovic, T., Turner, N., Vitha, M.F., Waller, M.P., Hibbs, D.E. and Clarke, R.J. (2006) Cholesterol Effect on the Dipole Potential of Lipid Membranes. Biophysical Journal, 90, 4060-4070. https://doi.org/10.1529/biophysj.105.074666

[22] Banerjee, S., Vandenbranden, M. and Ruysschaert, J. (1981) Interaction of Tobacco Mosaic Virus Protein with Lipid Membrane Systems. FEBS Letters, 133, 221-224.

[23] Schubert, D., Bleuel, H., Domninc, B. and Wiedner, G (1977) Protein-Induced Conductivity Changes in Black Lipid Membranes and Protein Aggregation. FEBS Letters, 74, 47-49.

[24] Liu, L. and Cleary, S. (1995) Absorbed Energy Distribution from Radiofrequency Electromagnetic Radiation in a Mammalian Cell Model: Effect of Membrane-Bound Water. Bioelectromagnetics, 171, 160-171. https://doi.org/10.1002/bem.2250160304

[25] Steck, T. (1974) The Organization of Proteins in the Human Red Blood Cell Membrane: A Review. The Journal of Cell Biology, 62, 1-19. https://doi.org/10.1083/jcb.62.1.1

[26] Kupiainen, M. and Falck, E. (2005) Free Volume Properties of Sphingomyelin, DMPC, DPPC, and PLPC Bilayers. Journal of Computational and Theoretical Nanoscience, 2, 401-413. https://doi.org/10.1166/jctn.2005.211

[27] Lee, B.W., Faller, R., Sum, A.K., Vattulainen, I., Patra, M. and Karttunen, M. (2004) Structural Effects of Small Molecules on Phospholipid Bilayers Investigated by Molecular Simulations. Fluid Phase Equilibria, 225, 63-68.

[28] Olsen, B. (2010) An Examination of Oxysterol Effects on Membrane Bilayers using Molecular Dynamics Simulations. Washington University, St. Louis.

[29] Campello, E.M.B. and Zohdi, T.I. (2014) Design Evaluation of a Particle Bombard- 
ment System Used to Deliver Substances into Cells. CMES, 98, 221-245.

[30] Pierro, V., De Vita, A., Croce, R.P. and Pinto, I.M. (2014) Membrane Heating in Living Tissues Exposed to Nonthermal Pulsed EM Fields. IEEE Transactions on Plasma Science, 42, 2236-2244. https://doi.org/10.1109/TPS.2014.2342492

[31] Reviakine, I., Rossetti, F.F., Morozov, A.N. and Textor, M. (2005) Investigating the Properties of Supported Vesicular Layers on Titanium Dioxide by Quartz Crystal Microbalance with Dissipation Measurements. The Journal of Chemical Physics, 122, Article ID: 204711. https://doi.org/10.1063/1.1908500

[32] Heikelä, M., Vattulainen, I. and Hyvönen, M.T. (2006) Atomistic Simulation Studies of Cholesteryl Oleates: Model for the Core of Lipoprotein Particles. Biophysical Journal, 90, 2247-2257. https://doi.org/10.1529/biophysj.105.069849

[33] Waxham, M.N. (2007) Molecular Mobility in Cells Examined with Optical Methods. Bean A. Protein Trafficking Neurons, 3-27.

[34] Liu, S.X. and Kim, J.-T. (2009) Application of Kevin-Voigt Model in Quantifying Whey Protein Adsorption on Polyethersulfone using QCM-D. Journal of the Association for Laboratory Automation, 14, 213-220.

[35] https://www.cst.com/

[36] Vasylchenko, A., Schols, Y., De Raedt, W. and Vandenbosch, G.A.E. (2009) Quality Assessment of Computational Techniques and Software Tools for Planar Antenna Analysis. IEEE Antennas and Propagation Magazine, 51, 23-38. https://doi.org/10.1109/MAP.2009.4939017

[37] Warshel, A., Sharma, P.K., Kato, M. and Parson, W.W. (2006) Modeling Electrostatic Effects in Proteins. Biochimica et Biophysica Acta, 1764, 1647-1676.

[38] Dutz, S. and Hergt, R. (2013) Magnetic Nanoparticle Heating and Heat Transfer on a Microscale: Basic Principles, Realities and Physical Limitations of Hyperthermia for Tumour Therapy. International Journal of Hyperthermia, 29, 790-800. https://doi.org/10.3109/02656736.2013.822993

[39] Andocs, G., Renner, H., Balogh, L., Fonyad, L., Jakab, C. and Szasz, A. (2009) Strong Synergy of Heat and Modulated Electro-Magnetic Field in Tumor Cell Killing, Study of HT29 Xenograft Tumors in a Nude Mice Model. Strahlentherapie und Onkologie, 185, 120-126. https://doi.org/10.1007/s00066-009-1903-1

[40] Vancsik, T., Andocs, G., Kovago, C.S., Papp, E., Meggyeshazi, N., Kiss, E. and Krenacs, T. (2015) Presentation at $33^{\text {rd }}$ Annual Conference of International Clinical Hyperthermia Society (ICHS), Bad Salzhausen, 11-13 July 2015.

[41] Andocs, G., Rehman, M.U., Zhao, Q.-L., Papp, E., Kondo, T. and Szasz, A. (2015) Nanoheating without Artificial Nanoparticles Part II. Experimental Support of the Nanoheating Concept of the Modulated Electro-Hyperthermia Method, using U937 Cell Suspension Model. Biology and Medicine Biology and Medicine, 7, 1-9. https://doi.org/10.4172/0974-8369.1000247

[42] Szasz, O. and Szasz, A. (2014) Oncothermia Nano-Heating Paradigm. Journal of Cancer Science and Therapy, 6, 4. https://doi.org/10.4172/1948-5956.1000259

[43] Szasz, A. (2013) Electromagnetic Effects in Nanoscale Range. In: Shimizu, T. and Kondo, T., Eds., Cellular Response to Physical Stress and Therapeutic Applications, Chapter 4, Nova Science Publishers, Inc.

[44] Andocs, G., Rehman, M.U., Zhao, Q.-L., Tabuchi, Y., Kanamori, M. and Kondo, T. (2016) Comparison of Biological Effects of Modulated Electro-Hyperthermia and Conventional Heat Treatment in Human Lymphoma U937 Cell. Cell Death Discovery, 2, 16039. https://doi.org/10.1038/cddiscovery.2016.39 
[45] Meggyeshazi, N., Andocs, G., Balogh, L., Balla, P., Kiszner, G., Teleki, I., Jeney, A. and Krenacs, T. (2014) DNA Fragmentation and Caspase-Independent Programmed Cell Death by Modulated Electrohyperthermia. Strahlentherapie und Onkologie, 190, 815-822. https://doi.org/10.1007/s00066-014-0617-1

[46] Andocs, G., Meggyeshazi, N., Balogh, L., Spisak, S., Maros, M.E., Balla, P., Kiszner, G., Teleki, I., Kovago, C.S. and Krenacs, T. (2014) Upregulation of Heat Shock Proteins and the Promotion of Damage-Associated Molecular Pattern Signals in a Colorectal Cancer Model by Modualted Electrohyperthermia. Cell Stress and Chaperones, 20, 37-46. https://doi.org/10.1007/s12192-014-0523-6

[47] Szasz, O., Szasz, A.M., Minnaar, C. and Szasz, A. (2017) Heating Preciosity-Trends in Modern Oncological Hyperthermia. Open Journal of Biophysics, 7, 116-144. https://doi.org/10.4236/ojbiphy.2017.73010

[48] Szasz, O. and Szasz, A. (2016) Heating, Efficacy and Dose of Local Hyperthermia. Open Journal of Biophysics, 6, 10-18. https://doi.org/10.4236/ojbiphy.2016.61002

[49] http://www.freepatentsonline.com/20150217099.pdf 